\title{
Sex-dependent foraging effort and vigilance in coal-crested finches, Charitospiza eucosma (Aves: Emberizidae) during the breeding season: evidence of female-biased predation?
}

\author{
Pedro Diniz
}

Programa de Pós-Graduação em Ecologia, Instituto de Biologia, Universidade de Brasília. 70790-075 Brasília, DF, Brazil. E-mail: pedrodinizalves@yahoo.com.br

\begin{abstract}
Sexual dimorphism in birds is often attributed to sexual selection, but another interpretation suggests the evolution of this phenomenon by natural selection. Predation may be an important selective pressure, acting mainly on females. In this study, I tested the latter hypothesis on the coal-crested finch (Charitospiza eucosma Oberholser, 1905) in a neotropical savanna of the Central Brazil (Cerrado). I used capture methods for ascertaining the sex ratio in the population, and focal observations to gather behavioral data. My results show that the sex ratio is skewed toward males (1:1.39). Males were more vigilant, vocalized for longer periods of time, and used higher perches than females. Females foraged more, spent more time on parental care and remained on the ground for longer periods than males. These results support the 'foraging effort hypothesis, suggesting that females are more preyed upon because they spend more time foraging. Ultimately, this may reflect the fact that females invest more on parental care than males. The sexdependent parental investment may favor the evolution of different antipredator strategies in males and females: the camouflage in females as a less efficient strategy than vigilance in males.
\end{abstract}

KEY WORDS. Birds; foraging behavior; predation risk; sex ratio; sexual dimorphism.

Sexual dimorphism is widely known in several species of birds (Andersson 1994, Owens \& Hartley 1998) and has been commonly associated with sexual selection (ANDERSSON 1994, Gray 1996, HÖraK \& Lebreton 1998). Another interpretation suggests that natural selection may favor the evolution of sexual dimorphism (BJORKLUND 1991) through predatory pressure (Gotmark et al. 1997). Empirical studies have documented differences in the patterns of survival (ANgelstam 1984, Sillett \& HOLMEs 2002, GARDNER et al. 2003) and predation (SARGEANT et al. 1984, GотмаRк et al. 1997, Pоsт \& Gotмark 2006a) between males and females. For instance, males of sexually dimorphic invertebrates, fish, and some birds seem to fall victims of predation more often than their female counterparts (MAGNHAGEN 1991, McKellar et al. 2009). These males may be more vulnerable because their behavior and morphological traits make them more conspicuous, contrasting with their cryptic or camouflaged females (conspicuity hypothesis: SLAGsvold et al. 1995, Huнта et al. 2003). However, conflicting evidence showing that predation may be greater in females of some sexually dimorphic species do exist (Kenward \& Marcstrom 1981, Sargeant et al. 1984, Gotmark et al. 1997, Post \& Gotmark 2006a).

In addition to the rates of predation, other relevant information in the context of sex-specific predation risk is the adult sex ratio (ASR) in bird populations. In a recent review, Donald (2007) demonstrated that adult males outnumbered females in several species of birds (see also Dobson 1987, BReITwisch 1989). A male-biased ASR was found in $60.4 \%(\mathrm{~N}=$ 86) of the population level estimates of passerine species; by contrast, $83 \%(\mathrm{~N}=140)$ of population-level estimates of offspring sex ratio (OSR) in birds did not differ from equality (Donald 2007). Pondering the OSR balanced, the author argued that the only explanation for a skewed ASR would be higher mortality in the rare sex (DonALD 2007), as demonstrated for species of fish (Maly 1970, McKellar et al. 2009) and birds (LehiKoinen et al. 2008). Alternatively, sex differences in dispersion (and migration) may also account for deviations from a balanced sex ratio, but are less common and have been rarely tested in birds (Donald 2007). According to the dispersal hypothesis, the sex that disperses more is rarer in stable populations (Stiver et al. 2007, Desjardins et al. 2008), and predominates in new populations (Fry et al. 1987). This pattern, however, is rare in empirical studies (Donald 2007). Anatidae populations, for example, which have more dispersive males than females (Gowaty 1993, Clarke et al. 1997), still show a predominance of males in stable populations (MAYR 1939, BOLEN 1970).

The hypothesis of sex differences in mortality as an explanation for the variation in adult sex ratio (DonALD 2007) is supported by estimates of survival for adult birds (e.g. GARDNER et al. 2003). However, few studies have attempted to explain 
intersexual differences in mortality (DonALD 2007). Studies on secondary sex ratio (nestling, fledgling, or immature periods) suggest that the rarer sex may be more vulnerable to starvation due to competitive exclusion (Arroyo 2002, Hipkiss et al. 2002) or lack of specific nutritional elements (MARTins 2004); or be more susceptible to diseases and parasites (Lehikornen et al. 2008) due to heterozygous inferiority (MYERs 1978) or lower physiological resistance (Bize et al. 2005). However, one of the most speculated explanations for a skewed ASR pertains the risk of predation (GoTMARK et al. 1997), and predicts that the rare sex is more vulnerable to it (usually females in birds: PosT \& Gotmark 2006a). Assuming that the predation-risk hypothesis is valid, the next question is: why would female birds fall victim of predation more often than their male counterparts (JAKOBSSON et al. 1995, ZuK \& Kolluru 1998)?

One possible answer involves the trade-off between foraging and predation risk (Lima \& Dill 1990, Dukas \& Kamil 2000), generated by differences in parental investment between males and females (sex role hypothesis: Gotmark et al. 1997, Post \& GotMark 2006b). More investment in foraging means less attention paid to predators, which makes an individual more prone to becoming prey in nature (DUKAs \& KamiL 2000). Foraging efforts also reduce the time spent in vigilance (Lima \& Dill 1990), a common antipredator tactic used by birds (CARO 2005). The 'sex role hypothesis' predicts that females consume more energy because they need to produce and incubate eggs, and to take care of their offspring during the breeding season (PERRINS 1996, Monaghan \& Nager 1997); during this period, they lose some of their capacity to fly (Veasey et al. 2000, Kullberg et al. 2002); females also take more risks than males when they select habitats for foraging (GotMARK \& Post 1996). Furthermore, differences in foraging strategies may also result in a femalebiased predation risk (Роsт \& Gotмark 2006b).

Here, I test some predictions of the 'foraging effort hypothesis' (Post \& Gotmark 2006a) to explain sex differences in predation risk in adults of a population of the coal-crested finch. During the breeding season, I evaluated whether 1) the sex ratio is male-biased; 2) females invest more in foraging; 3 ) females forage more on the ground; 4 ) males are in average more vigilant. The results are discussed in the context of sex differences in parental investment, and the evolution of antipredator strategies in males and females of the species.

\section{MATERIAL AND METHODS}

The study was conducted at the environmental protection area of the São Bartolomeu River, near Sobradinho $\left(15^{\circ} 39^{\prime}-15^{\circ} 42^{\prime} \mathrm{S}, 47^{\circ} 41^{\prime}-47^{\circ} 44^{\prime} \mathrm{W}\right)$, Distrito Federal, Central Brazil. A 265 ha plot was chosen for sampling based on the presence of savanna and grassland vegetation, which are the primary habitats of coal-crested finches (DinIz \& SANTOS 2010). Part of the area shows signs of a recent accidental fire. The region is close to rural farms and condominiums, as well as land claim- ant communities. Human interference is common, including regular extraction of wood. The climate in the area is tropical seasonal, with well defined wet and dry seasons (Silva et al. 2008).

The coal-crested finch, Charitospiza eucosma Oberholser, 1905 is a typical passerine of the savannas in the Cerrado Region (Sick 1997, MaCedo 2002, Diniz \& SANTOs 2010). This species has a strong sexual dimorphism: the male is characterized by the black of the crown, crest and chest; the female has an orange buff breast-belly, and gray-gold back (Sick 1997, DinIz \& SANTOS 2010). The life history of this species is poorly known (Borges \& Marini 2008). Coal-crested finches can be found solitary, in pairs, or in small to large flocks. They are social during the non-breeding season, and are frequently found in association with mixed-species flocks. The foraging behavior of coal-crested finches is unclear. According to anecdotal evidence, they eat mainly grass, fruits and insects. coal-crested Finches are versatile for a Neotropical passerine, using several foraging tactics. Gleaning is the most widely used foraging tactic, especially in the capture of grass fruits. They also hang and reach to feed on insects and fruits (Diniz \& SANTos 2010). The only direct evidence of their reproduction is one nest found in a savanna at the Distrito Federal (Borges \& MARINI 2008). A more detailed study of the breeding biology of the coal-crested finch points to a monogamous social system during the reproductive season (see Diniz \& SANTos 2010). The pair builds the nest and together take care of the offspring in the nestling and fledgling periods. Males defend their territory from courtship to the end of the nesting period (DinIz \& SANTOS 2010).

To evaluate the tertiary sex ratio in the population we sampled specimens with mist-nets in 2008 (January, May-October, and December) and 2009 (January-June). The average interval between samplings was 7.7 days (range $=0-109, \mathrm{~N}=67$ ), and the longest was109 days, between January and May 2008, due to logistical constraints. A non-seasonal sampling, such as the one adopted in this work, is important to avoid errors, because the sex ratio can vary seasonally (Svensson 1997, Kelly 1998). I used four (= mode) $12 \times 2.5$ m mist-nets on a regular sampling day (range $=1-8, N=67$ ). The mist-nets were placed randomly in the habitat and no method was used to attract individuals, to avoid overestimating the capture of one sex (Holmes et al. 1989, Sogge et al. 2001). However, during the breeding season the mist-nets were placed inside coal-crested finch territories, placed more than $100 \mathrm{~m}$ from the nest (the distance between the mist-net and the nest may influence the capture rate) (Nur et al. 2004). The mist-netting effort did not exceed one day in each territory. Juveniles were not counted. The mist-nets were usually opened in the period 06:00 to 10:00, starting at sunrise (mean $4.17 \mathrm{~h} \pm 2.3 \mathrm{DP}$, range $=0.67-10.7 \mathrm{~h}$, $\mathrm{N}=67$ ). This method has two advantages. First, it controls the effects of micro-spatial factors that may confound sex ratio estimates; second, it can be more effective than methods involving direct observation, since it avoids overestimation the 
sex that is more conspicuous to the observer. DOMÈnECH \& SENAR (1997) studied the influence of capture methods on age and sex of Serins, Serinus serinus Linnaeus, 1766 (Fringillidae), showing that mist-nets do not overestimate the sex ratio in favor of males or females. Moreover, mist nets are widely used in bird demographic studies (RALPH \& DunN 2004). Here, one hundred and five (105) individuals were captured in 1310.47 net-h (Fig. 1).

Behavioral observations were conducted to measure traits related to foraging and vigilance of adult birds, using the focal-animal method (Altmann 1974). The searches for the birds were conducted randomly in their habitat during part of the breeding season (September-November 2009: Diniz \& Santos 2010). Observations were made only between 06:00 to 10:00 and 16:00 to 18:00. I used 7-21 x 40 binoculars at a distance of approximately $20-30 \mathrm{~m}$. I considered only individuals in social breeding pairs. The behavior of the individual selected was measured with a chronometer in focal bouts (sample unit) limited to 420 seconds $(\mathrm{min}=60.5, \mathrm{~N}=86$, Tab. I). I also used a mini-recorder to measure accurately the proportion of time spent in each behavior on a focal bout. I did not sample two or more bouts of the same individual in one day. On average, I did $2.46 \pm 1.65$ SD foraging bouts/day (range $=1-7, \mathrm{~N}=35$ days), or $525.59 \pm 429.97 \mathrm{SD}$ seconds/day of observation (range $=60.54-1862.93$ ). In order to standardize the sampling, the bouts did not start until the bird was foraging, which avoids false estimates, for example, of singing males or incubating females. When the individual exhibited antipredator response to the observer during a bout, the bout was disregarded. A focal bout ended when the individual left the scope of the observer for more than 30 seconds (a tolerance). All focal bouts were conducted by a single observer (Diniz).

I collected variables related to the percentage of time (during one bout) the subject spent on the following behavioral categories: 1) foraging, 2) vigilance, 3) self-maintenance, 4) communication (calls, song), 5) fight (aggression, chases) and 6) parental care. I also took notes on the types of foraging sites (ground, shrub and tree), and the vertical use of the habitat (perch height: 0-1, 1-2, 2-4, > $4 \mathrm{~m}$ ). Shifts in flight were infrequent and always occurred at distances that were prohibitive to continue the focal bout. The focal-time-budget method is common in experimental and observational studies of foraging and antipredator behavior in birds (GotMARK et al. 1997, Post \& Gotmark 2006a, b, Avilés \& Bednekoff 2007, Chor et al. 2007).

Table I. Focal bouts and behavior of males and females of coal-crested finch during breeding season. Values expressed as mean \pm SE. Values of behavioral variables exhibited as mean of time percentage $(s) \pm 1 \mathrm{SE}$. The significance differences are expressed in asterisks $\left(0.05-0.001^{*} / 0.001-0.0001^{* *} /<0.0001^{* * *}\right)$. ns: not significant. The sample size was 33 , except for females 'Perch height', with $\mathrm{N}=32$.

\begin{tabular}{|c|c|c|c|c|c|}
\hline \multirow{2}{*}{ Data/variables } & \multirow{2}{*}{ Male } & \multirow{2}{*}{ Female } & \multicolumn{2}{|c|}{ Mann-Whitney } & \multirow{2}{*}{ All } \\
\hline & & & $\mathrm{U}$ & $P$ & \\
\hline Observation time (min) & 188.50 & 119.91 & - & - & 307.40 \\
\hline Sample size $(\mathrm{N})$ & 53 & $33(32)$ & - & - & $86(85)$ \\
\hline Bout duration (s) & $213.39 \pm 14.49$ & $216.19 \pm 17.54$ & - & - & $214.47 \pm 11.12$ \\
\hline Vigilance $(\%)^{\star \star \star}$ & $51.47 \pm 5.00$ & $19.37 \pm 4.38$ & 395.5 & $<0.0001$ & $39.15 \pm 3.88$ \\
\hline Foraging $(\%)^{\star \star}$ & $38.58 \pm 4.97$ & $68.76 \pm 5.74$ & 480.5 & 0.0005 & $50.16 \pm 4.07$ \\
\hline Ground foraging* & $24.73 \pm 4.22$ & $44.08 \pm 6.45$ & 573.5 & 0.0070 & $32.15 \pm 3.71$ \\
\hline Shrub foraging & $1.28 \pm 0.67$ & $8.28 \pm 3.37$ & 743.0 & ns & $4.12 \pm 1.40$ \\
\hline Tree foraging & $12.63 \pm 3.01$ & $15.80 \pm 5.39$ & 821.5 & ns & $13.85 \pm 2.77$ \\
\hline Self-maintenance (\%) & $14.36 \pm 3.24$ & $14.68 \pm 4.94$ & 828.0 & ns & $14.48 \pm 2.74$ \\
\hline Fight (\%) & $2.54 \pm 1.23$ & $0.51 \pm 0.51$ & 802.0 & ns & $1.76 \pm 0.78$ \\
\hline Parental care $(\%)^{*}$ & 0.00 & $6.05 \pm 3.12$ & 636.0 & 0.0340 & $2.32 \pm 1.23$ \\
\hline \multicolumn{6}{|l|}{ Comunication (\%) } \\
\hline Song** & $16.50 \pm 3.43$ & $0.43 \pm 0.43$ & 481.0 & 0.0005 & $10.34 \pm 21.09$ \\
\hline Alarm call & $4.52 \pm 1.48$ & $1.66 \pm 1.16$ & 749.5 & ns & $3.42 \pm 1.02$ \\
\hline Constant call & $20.75 \pm 4.99$ & $13.11 \pm 4.45$ & 711.5 & ns & $16.67 \pm 3.39$ \\
\hline \multicolumn{6}{|l|}{ Perch height (\%) } \\
\hline $0-1 \mathrm{~m}^{*}$ & $27.56 \pm 4.64$ & $54.06 \pm 6.36$ & 492.5 & 0.0010 & $37.54 \pm 3.98$ \\
\hline $1-2 m$ & $14.98 \pm 2.54$ & $19.03 \pm 4.24$ & 787.0 & ns & $16.5 \pm 2.24$ \\
\hline $2-4 m$ & $21.32 \pm 3.99$ & $13.83 \pm 4.41$ & 714.0 & ns & $18.51 \pm 3.00$ \\
\hline$>4 \mathrm{~m}^{*}$ & $31.09 \pm 6.02$ & $4.54 \pm 1.95$ & 496.0 & 0.0010 & $21.10 \pm 4.06$ \\
\hline
\end{tabular}


Shifts in hops or jumps between substrates were considered as 'foraging' if there was no communication to suggest vigilance; these types of movement are similar to the 'search time' of the tyrant flycatchers (FITZPATRICK 1980). It is difficult to separate foraging in flight from foraging at the starting substrate (often a tree) for a generalist forager such as coal-crested finch. Therefore, I considered foraging in flight and foraging in substrate of departure in the same category (e.g. foraging in the tree). The 'vigilance' was considered the moment not preceded by an attack when the subject positioned its head slightly above its horizontal body axis ('overt vigilance' according BEDNEKOFF \& LIMA 2005). Necessary precautions were taken not to confuse 'vigilance' with food-handling (Fernández-Juricic et al. 2007). I considered 'parental care' any behavior performed in the care of eggs, nestlings or fledglings (i.e. inside or outside the nest). The variable 'self-maintenance' refers to the preening, head-scratching, sunbathing or rest behaviors (see Post \& Gotmark 2006a, CHог et al. 2007, Maruyama et al. 2010). Post \& GotMARK (2006a) categorized just 'preening', while CHOr et al. (2007), studying a waterbird, isolated 'rest' of the variables considered here as 'selfmaintenance'. MaruYama et al. (2010) grouped preening, foot scratching and related behaviors in 'maintenance', and separated sleeping on 'inactivity'. The 'calls' were classified into constant and alarm calls (see detailed description in DINIZ \& SANTOS 2010). The first call concerns the constant communication with the subjects' mate partner. The second call was identified when the territory was invaded by intruders, or when the subject met potential predators (e.g. birds of prey, jays). The perch height was recorded in conjunction with any other variable (e.g. vigilance, foraging: PosT \& GotMARK 2006a).

The sex ratio was obtained by calculating the proportion of captured individuals of one sex over another. I performed Chi-square tests to assess the effect of temporal variables such as year (2008 vs. 2009) and breeding activity (breeding $\mathrm{x}$ nonbreeding season) on the sex ratio. The Yates correction for $2 \times 2$ contingency tables was applied. The behavioral data did not meet the assumption of normality required for parametric analysis. Therefore, the differences between males and females were analyzed with the Mann-Whitney test. More specifically, I compared the proportion of time individuals of each sex (median) spent in each behavior (or habitat use) within each focal bout. The tests were carried out with the help of the software BioEstat (Ayres \& Ayres-Jr 2007).

\section{RESULTS}

The sex ratio for the coal-crested finch population under study was 1.386 , skewed in favor of males (61 males: 44 females). Thus, the proportion of the population composed by males was 0.58 (WiLSON \& HaRdy 2002). The year $\left(\chi^{2}=0,32, \mathrm{df}=1, \mathrm{p}=0.571\right.$ ) and breeding activity $\left(\chi^{2}=3.48, \mathrm{df}=1, \mathrm{p}=0.097\right)$ did not influence sample composition. The predominance of males was more pronounced during the breeding season (Fig. 1).

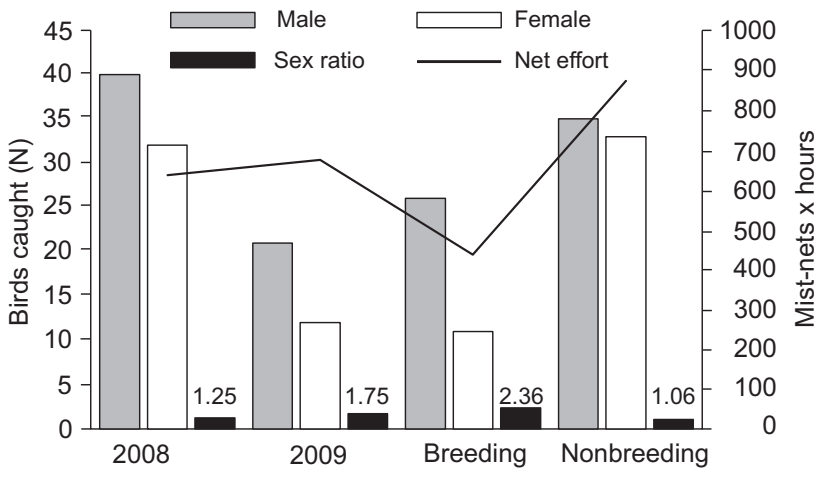

Figure 1. Sex ratio of a population of coal-crested finch from Central Brazil. Number of males and females captured and sample effort (mist-net $x$ hours) in relation to breeding activity and years. Breeding: September-December, February-April; nonbreeding: January, May-August (DINIZ \& SANTOS 2010).

Males were observed in 53 bouts and females in 33 . The total observation time was 307.4 minutes. Males and females differed in behavioral aspects that can directly influence the risk of predation. For example, males spent more than $50 \%$ of their time in vigilance, whereas females spent less than $20 \%$. Moreover, males sang $16 \%$ more times than females during focal bouts. This may be an indication that males spend considerably more time in activities related to courtship and territoriality. The substrate used for these activities was one of the highest perches available in the habitat, over four meters high $(31.09 \%)$. Females remained on these perches for only $4.54 \%$ of their time (Fig. 2, Tab. I).

Females spent more time than males foraging and in parenting care. Females foraged $68.76 \%$ of the time, contrasting with males who foraged only $38.58 \%$ of the time. In addition, females outnumbered males in all foraging sites (ground, shrub or tree). This tendency was particularly more pronounced on the ground, where females foraged significantly more than males. Females were engaged in parental care such as incubation and feeding of nestlings and fledglings more often than their partners. Still, these activities contributed to only $6.05 \%$ of the time used by females. In addition to foraging, females of the coalcrested finch remained on the ground for more than $54 \%$ of the time, contrasting significantly with males (27.6\%, Fig. 2, Tab. I).

Males and females did not differ significantly in other behaviors and habitat used. Both spent about $14 \%$ of the time doing 'self-maintenance'. They also spent some of their time in fights. The percentage of time spent foraging in shrubs and trees also did not differ. The same was true for communication behaviors: constant calls and alarm calls. Females remained on perches ' $1-2$ ' and ' $2-4$ ' $\mathrm{m} 14.95 \%$ and $21.32 \%$ of the time, respectively, whereas males spent $19.03 \%$ of the time on perches ' $1-2$ ' and $13.83 \%$ on perches ' $2-4$ ' $\mathrm{m}$ (Fig. 2, Tab. I). These differences were not statistically significant. 


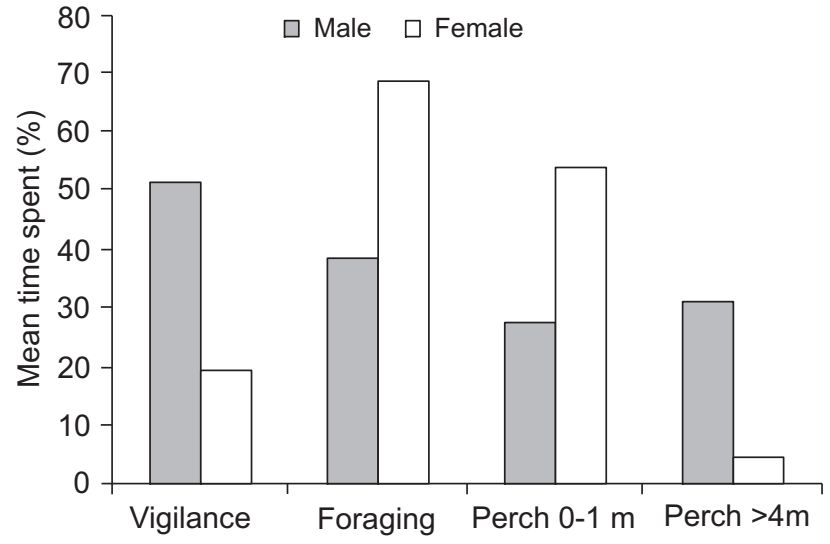

Figure 2. Behavioral and perch height use differences between male and female coal-crested finch during breeding season. These characterestics can be relationed to sex differences in predation risk.

\section{DISCUSSION}

\section{Sex ratio}

The adult male-biased sex ratio found for the coal-crested finch population under study (0.58) corroborates the ASR pattern found for several other species of birds (mean and median $0.57, \mathrm{~N}=173$ species), mainly Passeriformes (review in DonALD 2007). The data from this study is not sufficient to rule out the dispersal-hypothesis as an explanation for the ASR in coalcrested finches (DALE 2001). This is because the dispersion of females in birds can directly affect the ASR in favor of males (SANDERCOCK et al. 2000), and coal-crested finches are apparently semi-nomadic (Diniz \& SANTOS 2010). The ASR can also be directly or indirectly a result of ontogenetic (age-at-maturity: Girondot \& Pieau 1993, Rubolini et al. 2004), phylogenetic (Donald 2007), ecological - fluctuation of food resources: Clutton-Brock et al. (1991); spatial and temporal scales: Consuegra \& Leaniz (2007); presence of predators: McKellar et al. 2009 -, and social factors - mating system: PröHL (2002); sexual competition: Leturque \& Rousset (2004) - . However, mortality (or less survival) is the most widely supported hypothesis to explain deviations of ASR in natural populations, even in populations with strongly sex-biased dispersal (WILLIAMS \& RABENOLD 2005). In adult birds, mortality is greater or survival is lower in females (review in Donald 2007). For example, survival models with mark-resighting data estimated a higher survival of males in male-biased populations of the Blackthroated blue Warbler Dendroica caerulescens Gmelin, 1789 (Parulidae) (survival probability $=0.51$ vs. 0.43 for female, SILLETT \& Holmes 2002) e Speckled Warbler Chthonicola sagittata Latham, 1801 (Acanthizidae) (mortality: 37\% in females and 14\% in males, GARDNER et al. 2003).

Predation stands out as a cause of bird mortality (KENWARD \& Marcstrom 1981, Sargeant et al. 1984, O’Donnell 1996,
Gotmark et al. 1997, Post \& Gotmark 2006a). Even though it is still not possible to precisely identify the selective pressures that have shaped the evolution of ASR in coal-crested finches, it is very likely that adults are under some degree of selection by predation. Attempts made by Falco species to catch adult coal-crested Finches have been recorded, and may not be unusual; in addition, coal-crested finches exhibit a variety of antipredator behaviors (DINIZ \& SANTOS 2010). The male-biased sex ratio pattern was also observed in the White-banded Tanager Neothraupis fasciata (Lichtenstein, 1823) (Thraupidae) (C.G. Duca unpubl. data 2007), a species commonly associated with the coal-crested finch in mixed flocks (Diniz \& SANTOS 2010). Syntopic (or sympatric) prey species may have predators in common, as observed in the Eurasian blackbird Turdus merula Linnaeus, 1758 (Turdidae), the Pied flycatcher Ficedula hypoleuca Pallas, 1764 (Muscicapidae) and the Chanffinch Fringilla coelebs Linnaeus, 1758 (Fringillidae), which are predated by the European sparrohawk Accipiter nisus Linnaeus, 1758 (Accipitridae). Alternatively, mortality may be caused by starvation (ADAMs \& Frederick 2009) or increased susceptibility to diseases and parasites (SWennen et al. 1979, Bize et al. 2005, LehiKoinen et al. 2008). Sex-related starvation is unlikely in adults of coal-crested finches because males and females have similar physical constitutions (DINIZ \& SANTOS 2010). Parasitism was not observed in adults in the population studied and nestlings from the same clutch did not differ in the rate of parasitism (pers. obs.).

Other hypotheses based on parental investment (offspring sex ratio: OSR) offer alternative explanations (CLARK 1978, EMLEN et al. 1986). Assuming that parental investment is selected individually, adaptive differences in the production of males and females may occur (LeTurque \& Rousset 2004). The trade-off between dispersing and staying within the parental territory (cost-benefit of competition and cooperation with parents) may influence the evolution of the OSR (CLARK 1978, EmLen et al. 1986, Leturque \& Rousset 2004). However, the OSR does not vary much from the expected equal proportions in populations of birds and mammals: 8 in 10 male-biased sex ratio bird species have balanced OSR (DonALD 2007). Balanced OSR is also found in Neotropical birds (SOUTH \& WRIGHT 2002, BudDen \& BeIsSinger 2004). The balanced OSR in the population of the coal-crested Finch is an important premise required to test whether mortality is higher in females than in adult males, and corroborates the results found here in this study (DonALD 2007). I suggest that, in the future, assessments of the OSR are conducted for the coal-crested finch. In polygynous mammals, for example, the OSR and dispersal patterns, both male-biased, determine the ASR (Letuque \& Rousset 2004).

Alternatively, previous studies on adult mortality in populations with skewed ASR and OSR balanced, showed that sex-specific mortality is more prevalent in juvenile birds - secondary sex ratio SSR: Arroyo (2002), Hipkiss et al. (2002), LehiKoINen et al. (2008) - . In a population of the Common Eider, Somateria mollissima Linnaeus, 1758 (Anatidae) with the 
same OSR $(1: 1, N=418)$, carcasses of juvenile females predominanted $(59 \%, \mathrm{~N}=118)$. But a deviation of the SSR should not occur in coal-crested finch populations, since there are no sex differences in body mass of nestlings and fledglings, common in species with biased SSR (ARroyo 2002, Hipkiss et al. 2002).

Few methods of measuring ASR are a priori unbiased, including genetic analyzes of fecal droppings or shed feathers, removal experiments or molecular sexing of prey remains or carcasses (Donald 2007); but estimates of sex ratio have provided indirect support for higher female mortality in birds (see above). Here, the capture of females of the coal-crested finch may have been underestimated because they differed from males in foraging effort, microhabitat selection (time spent on the ground) and parental care in the breeding season. In the nonbreeding season, by contrast, males and females foraged in mixed flocks using the same tactics and microhabitat, and yet males predominated in the population. The similarity of the results (i.e. male biased sex ratio) of studies using different sampling techniques put in question the influence of the methodology used on large deviations from a balanced sex ratio (Darley 1971, Barrentine et al. 1990, Kelly 1998, Sogge et al. 2001, Sillett \& Holmes 2002, SANDercock et al. 2005, TAYlor \& PARKIN 2008). WheelWright et al. (1994), for example, used a similar mist-net method andregistered a female biased ASR in the Savannah Sparrow Passerculus sandwichensis Gmelin, 1789 (Emberizidae) (see also Humple et al. 2001). Finally, the recent history of fragmentation of the natural habitat of the coalcrested finch (and birds of the Cerrado) (CARvalHo et al. 2009), may have affected the sex ratio of local populations (ColLins \& BarRetT 1997, Sun et al. 2003, Banks et al. 2005).

\section{Foraging effort vs. vigilance}

Sex-specific foraging effort is well described in birds, primarily waterbirds (Gilardi 1992, SAlamolard \& Weimerskirch 1993, Clarke 2001, GonZález-Solís et al. 2000, Lewis et al. 2002, COOK et al. 2007, BREED et al. 2009), and is often attributed to differences in body mass, morphology and diet, and evolutionary constraints such as sex roles and competitive interference (Clarke 2001, Lewis et al. 2002, Cook et al. 2007). The consequences of sex-specific foraging effort are less known, but observational studies have demonstrated that foraging effort may affect predation in a positive manner (GoTMARK et al. 1997, Post \& Gotmark 2006a, b). In coal-crested finches, males were more vigilant, whereas females spent more time foraging, corroborating the 'foraging effort hypothesis' (Post \& GOTMARK 2006a) to explain female-biased predation risk patterns in bird populations (Shreeve 1980, Kenward \& Marcstrom 1981, Angelstam 1984, Sargeant et al. 1984, Gotmark et al. 1997, Post $\&$ Gotmark 2006a). In this sense, the greater proportion of males in the population of the coal-crested finch may be due to a greater foraging effort on the part of females.

Studies with Passeriformes in north temperate zones support the 'foraging effort hypothesis' (GoTMARK et al. 1997, PosT
\& Gotмarк 2006ab). The Eurasian sparrohawk Accipiter nisus is an important predator of Passeriformes in this region (GoTMARK $\&$ Post 1996). Females of one of its prey, the Eurasian blackbird, are predated upon more often than males $(57 \%$ of 98 remains of adult blackbirds in the nests of Eurasian sparrowhawk), and forage for up to $69 \%$ of the time during the breeding season (Post \& GotMARK 2006a). I have found a very similar value $(68.76 \%)$ in this study for the coal-crested finch. In Pied flycatcher, females devote more effort to foraging and are 4.7 times more vulnerable than males per unit of time outside the nest. These results are based on prey remains found in the nests of the Eurasian Sparrowhawk (Post \& Gotmark 2006b). GoтмARк et al. (1997) showed that females foraged 20\% longer than males and accounted for $70 \%$ of the chaffinches in the nests of Eurasian Sparrowhawks, and that Sparrowhawks do not select their prey according to gender. The authors of these studies did not measure the time spent in vigilance, but assumed the hypothesis of Lima \& Dill (1990), in which foraging and vigilance tend to not overlap in time. Gotmark et al. (1997) suggested that chaffinches are moving about $90 \%$ of the time, either foraging or on other activities. In the coal-crested finch, the time spent on vigilance can be considered high, even considering females.

\section{Foraging site vs. predation risk}

The empirical argument in favor of foraging effort as an explanation for increased predation risk is well-known, but other predictions in foraging behavior also begin to emerge. Some studies argue that birds foraging on the ground would be more exposed to predators and have fewer opportunities to escape an attack (Selas 1993, Gotmark \& Post 1996, Post \& GotMARк 2006a). The inverse relationship between predation risk and exposure is known (SeLAs 1993, Post \& GotMARK 2006b), suggesting that avoiding the ground might be an antipredator strategy adopted by forest birds (Gotmark \& POst 1996). An adaptive antipredator function may also be attributed to sexspecific habitat selection in other taxa (beetles: Romey \& WaLLACE 2007, buffalo: Hay et al. 2008). Females of the pied flycatcher, for example, chose higher foraging sites (over $3 \mathrm{~m}$ ) than males, what may well be an adaptive response to predation (Post \& GotMARK 2006b). Chaffinches behave differently: individuals forage on the ground or close to it, which may also be related to female-biased predation (Gotmark et al. 1997). The coalcrested finch is a typical ground foraging species, where it may eat grass fruits and arthropods (DINIZ \& SANTOS 2010). However, there is a sex-specific use of the ground: coal-crested finch females use the ground to forage, and as a substrate for other activities more than twice as much as males. This pattern complements and supports the hypothesis of foraging effort and female-biased predation in the coal-crested finch. Assuming the costs of predation for coal-crested finch females, microhabitat choice could have evolved in response to other pressures such as sexual niche segregation (PhilLips et al. 2004), competitive interference (Peters \& Grubb 1983, Ardia \& Bildstein 
1997), differences in nutritional requirements (Lewis et al. 2002), or parental investment (GotMark et al. 1997, Post \& Gotmark 2006b).

\section{Parental investment}

Males of the coal-crested finch build the nest, render parental care to nestlings and fledglings, but do not incubate the eggs. By contrast, females are present in all of these activities (DinIZ \& SANTOS 2010). In this study, males were not observed rendering parental care, and females spent only about $6 \%$ of their time on it. These results, which suggest that parental care by both sexes is limited, may be a reflexion of the fact that our focal observations focused on foraging subjects. Males of the coal-crested finch, however, used time to sing (16.5\%). Behaviors associated with male-male competition for territory and mating, which include the rate of singing, can make an individual more likely to be detected by a predator (SLAGSVold et al. 1995, Dale \& Slagsvold 1996, Montgomerie et al. 2001). But singing only may not, in and on itself, decrease vigilance (KRAMS 2001). Another evidence in support of a male-biased predation risk is the fact that breeding males form clusters. Territorial clustering, similar to leks, as observed in coal-crested finches (Diniz \& SANTOS 2010), can attract predators and increase the risk of predation for males (TRAIL 1987, HALE 2004); alternatively it can have the opposite effect, reducing predation risk through dilution effect or predator deterrence (GIBSON et al. 2002, Perry \& Andersen 2003).

Parental investment may be the most important factor determining the different degrees of vulnerability of each sex to predation (sex role hypothesis: Gotmark et al. 1997, Post \& Gotmark 2006b). Physiological approaches show that females consume more energy during the breeding season. For birds, the cost may be higher during egg production and incubation (Tinbergen \& Dietz 1994, Ward 1996). Some researchers have established a simple relationship between energy demand and the increase in foraging effort, with consequent reduction in vigilance (Lima \& Dill 1990, Lima \& Bednekoff 1999, Dukas \& KAMIL 2000). Again, the result would be a female-biased predation risk. For males, the reproductive activities (e.g. singing) are not so energetically demanding (OBERWEger \& Goller 2001).

Parental investment also directly affects the risk of predation in adult birds (STOleson \& BeISINGER 2001), as it has been demonstrated for breeding ducks in north temperate zones (Sargeant 1972, Sargeant \& Eberhardt 1975, Sargeant et al. 1984). SARgEANT (1972) found a high proportion of carcasses of female ducks $(84 \%, \mathrm{~N}=129)$ in rearing dens of the Red fox, Vulpes vulpes Frisch, 1775 (Canidae) and that predation coincides with the duck breeding season and egg incubation (SARGEANT et al. 1984). Males may differ from females in the risk of predation during the provisioning phase. In males of the Collared flycatcher, Ficedula albicollis Temminck, 1815 (Muscicapidae) predation risk is related to brood value and survival chances, whereas in females it is related to the broods' vulnerability (Michl et al. 2000).

\section{Evolution of antipredator strategies}

Because the rate of predation is high for females of the coal-crested finch, their cryptic plumage may have evolved as an antipredator strategy (GoTMARK et al. 1997). Females are not subjected to the mate attraction-predation risk trade-off which usually modulates the color pattern of males in dimorphic species (ENDler 1991, Godin \& McDonough 2003, Figueirola \& Senar 2007). However, in a few cases, the conspicuity of males negatively affects the risk of predation for females (PocKLINGTON \& Dill 1995), suggesting a correlation selection. Slagsvold et al. (1995) observed the rate of disappearance of adult pied flycatchers during the breeding season, and found that "dull males" (with a color pattern more similar to that of females) did not disappear $(0 \%)$, contrasting with "bright males" and females (11\% of which disappeared). This suggests that the cryptic plumage has antipredator function, and that another females' vulnerability to predation (e.g. a greater foraging effort) is worsened by something else. In chaffinches, GotMark (1993) showed that stuffed cryptic females may be less detected by predators than stuffed conspicuous males (10 vs. 23 attacks). However, the characteristics that lead predators to chose their prey, such as how cryptic the prey is and what gender it belongs to, may vary among prey species (GoTMARK 1993). For this reason, it is necessary to understand the mechanisms that determine a predators' choice of prey. Some aposematic males, for example, may be able to avoid predation in spite of being easily detectable (Gotmark \& Unger 1994). Figueirola \& Senar (2007) identified a stabilizing natural selection on the coloration of Serins (Serinus Serinus). In this species, it is possible that individuals with drabber plumage have lower survival rates because they are more parasitized (Figueirola et al. 2003), whereas individuals with bright plumage, who invest more in the acquisition of partners, are more vulnerable to predation. Future studies need to test these hypotheses (aposematic, detectability) for the coal-crested finch.

The evidence showing that cryptic plumage has an antipredator function for adult females (GoTMARK et al. 1997) does not corroborate the hypothesis that cryptic plumage has been selected because it decreases nest predation (MArTin \& BADYAEV 1996). In the tropics, nest predation appears to be a stronger selective pressure than in north temperate zones (WILLIS 1961, GILL 1989). However, both the 'adult defense' and the 'nest defense' hypotheses are not antagonistic and can be co-adaptive mechanisms. Studies on the trade-off between 'investing in breeding now' and 'surviving and breeding in the future' (CANDOLIN 1998) may contribute to the understanding of the evolution of cryptic females (DALE \& SLAGSVOLD 1996), because it is important to distinguish the magnitude of the predatory selective pressures involved (i.e. nest vs. adult predation). An alternative strategy can evolve in females: manipulating the vigilance of mate partners could be beneficial for females because it allows more investment in foraging while reducing predation risk (Gotmark et al. 1997, Post \& GotMark 2006b). 
Male coal-crested finches may suffer a lower predation pressure which is consistent with the foraging effort hypothesis (Post \& Gotmark 2006a). An individual may respond to increased predation risk with an increase in vigilance (LiMA \& Dill 1990, van Der Veen 1999). In males, antipredator vigilance can evolve more efficiently because they have fewer restrictions and might be able to coordinate vigilance with social monitoring (territoriality) and nest defense. This scenario is advantageous for the sexual pressure on the evolution of secondary characters in males, making males more conspicuous and ornamented, as males of the coal-crested finch.

This study investigated the relationship between foraging and predation risk to explain the differences in the proportion of males and females in populations of a Neotropical bird. Population demography sampling and comparative behavioral observations showed that 1) the number of females was smaller in populations of the coal-crested finch, and that 2) females need to forage more than males. These results may indicate that females of this species are more vulnerable to predation than males. However, further studies are needed to ascertain whether predation is actually more frequent in females of coal-crested finch, or in other Neotropical bird species, than in males. I suggest that observations on the foraging behavior of predators (STEVENS et al. 2009), monitoring prey social groups in the breeding season (STOLESON \& BeISSINGER 2001), and the choice of a model of abundant prey population, are important to test the female-biased predation hypothesis.

\section{ACKNOWLEDGMENTS}

I thank Desirée Ramos for logistical support for data collection and technical suggestions to the manuscript; Rafael Nunes by theoretical questions and suggestions to work; Renato Gama for help with the translation of the manuscript; the editors and two anonymous reviewers for their valuable suggestions to the manuscript.

\section{LITERATURE CITED}

Adams, J. \& P. Frederick. 2009. Sex-related mortality of White Ibis (Eudocimus albus) nestlings during a starvation event. Waterbirds 32 (1): 123-127.

Altmann, J. 1974. Observational study of behavior: sampling methods. Behaviour 49 (3-4): 227-267.

Andersson, M. 1994. Sexual selection. New Jersey, Princeton University Press, 599p.

Angelstam, P. 1984. Sexual and seasonal differences in mortality of the Black Grouse Tetrao tetrix in Boreal Sweden. Ornis Scandinavica 15 (2): 123-134.

ARdia, D. \& K. Bildstein. 1997. Sex-related differences in habitat selection in wintering American kestrels, Falco sparverius. Journal of Avian Biology 33 (4): 455-460.

Arroyo, B. 2002. Sex-biased nestling mortality in the Montagu's harrier Circus pygargus. Journal of Avian Biology 33 (4): 455-460.

Avilés, J.M. \& P.A. BedneKoff. 2007. How do vigilance and feeding by common cranes Grus grus depend on age, habitat, and flock size? Journal of Avian Biology 38: 690-697.

Ayres, M. \& M. Ayres-Jr. 2007. BioEstat 5.0: aplicações estatísticas nas áreas das ciências bio-médicas. Belém. Available online at: http://www.mamiraua.org.br/download/ [Accessed: 30.XI.2009].

Banks, S.; G.R. Finlayson; S.J. Lawson; D.B. Lindenmayer; D. Paetkau; S.J. WARD \& A.C. TAYLOR. 2005. The effects of habitat fragmentation due to forestry plantation establishment on the demography and genetic variation of a marsupial carnivore, Antechinus agilis. Biological Conservation 122 (4): 581-597.

Barrentine, C.; C. Corchran \& M. Lincoln. 1990. Comparative age and sex ratios in Gambel's White crowned sparrows in relation to year and latitude. North American Bird Bander 15 (2): 57-60.

BeDneKoff, P.A. \& S.L. Lima. 2005. Testing for peripheral vigilance: do birds value what they see when not overtly vigilant? Animal Behaviour 69: 1165-1171.

Bize, P.; A. Roulin; J.L. Tella \& H. Richner. 2005. Female-biased mortality in experimentally parasitized Alpine Swift Apus melba nestlings. Journal of Evolutionary Biology 4: 83-92.

BJORKLUND, M. 1991. Coming of age in fringillid birds: heterochrony ontogeny of secondary sexual characters. Journal of Evolutionary Biology 4: 83-92.

Bolen, E.G. 1970. Sex ratios in the Black-bellied tree duck. The Journal of Wildlife Management 34 (1): 68-73.

Borges, F.J. \& M.Â. Marini. 2008. Primeira descrição do ninho do mineirinho (Charitospiza eucosma) no cerrado Brasil Central. Revista Brasileira de Ornitologia 16 (1): 38-39.

Breed, G.A.; Jonsen, I.D.; Myers, R.A.; Bowen, W.D. \& M.L. LEONARD. 2009. Sex-specific, seasonal foraging tactics of adult prey seals (Halichoerus grypus) revealed by state-space analysis. Ecology 90 (11): 3209-3221.

BReITWISCH, R. 1989. Mortality patterns, sex ratios, and parental investment in monogamous birds. Current Ornithology 6: $1-50$.

Budden, A.E. \& S.R. Beissinger. 2004. Against the odds? Nestling sex ratio variation in green-rumped parrotlets. Behavioral Ecology 15 (4): 607-613.

CANDolin, U. 1998. Reproduction under predation risk and the trade-off between current and future reproduction in the threespine stickleback. Proceedings of the Royal Society of London Series B 265: 1171-1175.

Carvalho, F.M.V.; P.M. Júnior \& L.G. Ferreira. 2009. The Cerrado into-pieces: Habitat fragmentation as a function of landscape use in the savannas of central Brazil. Biological Conservation 142 (7): 1392-1403.

CARO, T. 2005. Antipredator defenses in birds and mammals. Chicago, University of Chicago Press, 591p. 
Chol, C.; H. Nam \& W. LeE. 2007. Measuring the behaviors of wintering Black-faced Spoonbills (Platalea minor): comparison of behavioral sampling techniques. Waterbirds 30 (2): 310316.

Clark, A.B. 1978. Sex ratio and local resource competition in a prossimian primate. Science 201: 163-165.

Clarke, A.L.; B. Saether \& E. Roskaft. 1997. Sex biases in avian dispersal: a reappraisal. Oikos 79 (3): 429-438.

Clarke, J.R. 2001. Partitioning of foraging effort in Adélie penguins provisioning chicks at Béchervaise Island, Antarctica. Polar Biology 24: 16-20.

Clutton-Brock, T.H.; O.F. Price; S.D. Albon \& P.A. Jewell. 1991. Persistent instability and population regulation in Soay Sheep. Journal of Animal Ecology 60 (2): 593-608.

Collins, R.J. \& G.W. Barrett. 1997. Effects of habitat fragmentation on meadow vole (Microtus pennsylvanicus) population dynamics in experimental landscape patches. Landscape Ecology 12: 63-76.

Consuegra, S. \& C.G. Leániz. 2007. Fluctuating sex ratios, but no sex-biased dispersal, in a promiscuous fish. Evolutionary Ecology 21 (2): 229-245.

Cook, T.R.; Y. Cherel; C. Bost \& Y. Tremblay. 2007. Chick-rearing Crozet shags (Phalacrocorax melanogenis) display sex-specific foraging behaviour. Antartic Science 19 (1): 55-63.

Dale, S. \& T. Slagsvold. 1996. Plumage coloration and conspicuousness in birds: experiments with the Pied Flycatcher. The Auk 113 (4): 849-857.

DALE, S. 2001. Female-biased dispersal, low female recruitment, unpaired males, and the extinction of small and isolated bird populations. Oikos 92 (2): 344-356.

Darley, J.A. 1971. Sex ratio and mortality in the Brown-headed Cowbird. The Auk 88 (3): 560-566.

Desjardins, J.K.; J.L. Fitzpatrick; K.A. Stiver; G.J. van der KraAk; S. BALSHINE. 2008. Costs and benefits of polygyny in the cichlid. Animal Behaviour 75 (5): 1771-1779.

Diniz, P. \& E.S.A. SANTos. 2010. Coal-crested Finch (Charitospiza eucosma), Neotropical Birds Online. Ithaca, Cornell Lab of Ornithology. Available online at: http://neotropical.birds. cornell.edu/portal/species/overview?p_p_spp = 645996 [Accessed: 24/V/2010].

Dobson, A.P. 1987. A comparison of seasonal and annual mortality for both sexes of fifteen species of common British birds. Ornis Scandinavica 18: 122-128.

Domènech, J. \& K.C. Senar. 1997. Trapping methods can bias age ratio in samples of passerine populations. Bird Study 44: 348-354.

Donald, P.F. 2007. Adult sex ratios in wild bird populations. Ibis 149: 671-692.

Dukas, R. \& A.C. Kamil. 2000. The cost of limited attention in blue jays. Behavioral Ecology 11 (5): 502-506.

EmLen, S.T.; J.M. Emlen \& S.A. Levin. 1986. Sex-ratio selection in species with helpers-at-the-nest. The American Naturalist 127: 1-8.
ENDLER, J.A. 1991. Variation in the appearance of guppy colour patterns to guppies and their predators under different visual conditions. Vision Research 31: 587-608.

Fernández-Juricic, E.; G. Beauchamp \& B. Bastain. 2007. Groupsize and distance-to-neighbour effects on feeding and vigilance in brown-headed cowbirds. Animal Behaviour 73: 771-778.

Figueirola, J.; J. Domènech \& J.C. Senar. 2003. Plumage colour is related to ectosymbiont load during moult in the serin, Serinus serinus: an experimental study. Animal Behaviour 65: 551-557.

Figueirola, J. \& J.C. Senar. 2007. Serins with intermediate brightness have a higher survival in the wild. Oikos 116: 636-641.

Fitzpatrick, J.W. 1980. Foraging behavior of Neotropical Tyrant flycatchers. The Condor 82 (1): 43-57.

FrY, D.M.; C.K. Toone; S.M. Speich; R.J. Peard. 1987. Sex ratio skew and breeding patterns of gulls: demographic and toxicological considerations. Studies in Avian Biology 10: 26-43.

Gardner, J.L.; R.D. Magrath \& H. Kokko. 2003. Stepping stones of life: natal dispersal in the group-living but noncooperative speckled warbler. Animal Behaviour 66: 521-530.

Gibson, R.M.; A.S. Aspbury \& L.L. McDaniel. 2002. Active formation of mixed grouse leks: a role for predation in lek evolution? Proceedings Biological Sciences 269 (1509): 2503-2507.

GILARDI, J.D. 1992. Sex-specific foraging distributions of brown boobies in the Eastern Tropical pacific. Colonial Waterbids 15 (1): 148-151.

GILL, F.B. 1989. Ornithology. New York, W.H. Freeman, 660p. Girondot, M. \& C. Pieau. 1993. Effects of sexual differences of age at maturity and survival on population sex ratio. Evolutionary Ecology 7 (6): 645-650.

Godin, J.J. \& H.E. McDonough. 2003. Predator preference for brightly colored males in the guppy: a viability cost for a sexually selected trait. Behavioral Ecology 14 (2): 194-200.

González-Solís, J.J.P. Croxall \& A.G. Wood. 2000. Sexual dimorphism and sexual segregation in foraging strategies of northern giant petrels, Macronectes halli, during incubation. Oikos 90 (2): 390-398.

Gotmark, F. 1993. Conspicuous coloration in male birds is favoured by predation in some species and disfavoured in others. Proceedings of the Royal Society of London Series B 253: 143-146.

Gotmark, F. \& U. Unger. 1994. Are conspicuous birds unprofitable prey? Field experiments with hawks and stuffed prey species. The Auk 111 (2): 251-262.

Gotmark, F. \& P. Post. 1996. Prey selection by sparrowhawks, Accipiter nisus: relative predation risk for breeding passerine birds in relation to their size, ecology and behaviour. Philosophical Transactions of the Royal Society of London Series B 351: 1559-1577. 
Gotmark, F; P. Post; J. Olsson \& D. Himmelmann. 1997. Natural selection and sexual dimorphism: sex-biased Sparrowhawk predation favours crypsis in female Chaffinches. Oikos 80 (3): 540-548.

Gowaty, P.A. 1993. Differential dispersal, local resource competition, and sex ratio variation in birds. The American Naturalist 141 (2): 263-280.

GraY, D.A. 1996. Carotenoids and sexual dichromatism in North American passerine birds. The American Naturalist 148: 453-480.

HaLe, A.M. 2004. Predation risk associated with group singing in a neotropical Wood-qual. The Wilson Bulletin 116 (2): $167-171$

Hay, C.T.; P.C. Cross \& P.J. Funston. 2008. Trade-offs of predation and foraging explain sexual segregation in African buffalo. Journal of Animal Ecology 77: 850-858.

Hipkiss, T.; B. Hörnfeld; U. Eklund \& S. Berlin. 2002. Yeardependent sex-biased mortality in supplementary-fed Tengmalm's owl nestlings. Journal of Animal Ecology 71 (4): 693-699.

Holmes, R.T.; T.W. Sherry \& L. Reitsma. 1989. Population structure, territoriality and overwinter survival of two migrant Warbler species in Jamaica. The Condor 91(3): 545561.

Hõrak, P. \& J. Lebreton. 1998. Survival of adult Great Tits Parus major in relation to sex and habitat; a comparison of urban and rural populations. Ibis 140: 205-209.

Huhta, E.; S. Rytkonen \& T. Solonen. 2003. Plumage brightness of prey increases predation risk: an among-species comparison. Ecology 84 (7): 1793-1799.

Humple, D.L.; N. Nur; G.R. Geupel \& M.P. Lynes. 2001. Femalebiased sex ratio in a wintering population of Ruby-crowned Kinglets. The Wilson Bulletin 113 (4): 419-424.

Jakobsson, S.; O. Brick \& C. Kullberg. 1995. Escalated fighting behaviour incurs increased predation risk. Animal Behaviour 49: 235-239.

Kelly, J.F. 1998. Latitudinal variation in sex ratios of Belted Kingfishers. Journal of Field Ornithology 69 (3): 386-390.

Kenward, R.E \& V. Marcstrom. 1981. Goshawk winter ecology in Swedish pheasant. Journal of Wildlife Management 45: 397-408.

Krams, I. 2001. Perch selection by singing chaffinches: a better view of surroundings and the risk of predation. Behavioral Ecology 12: 295-300.

Kullberg, C.; N.B Metcalfe \& D.C. Houston. 2002. Impaired flight ability during incubation in the pied flycatcher. Journal of Avian Biology 33: 179-183.

Lehikoinen, A.; M. Öst; T. Hollmén \& M. Kilpi. 2008. Does sexspecific duckling mortality contribute to male bias in adult Common Eiders. The Condor 110 (3): 574-578.

Leturque, H. \& F. Rousset. 2004. Intersexual competition as an explanation for sex-ratio dispersal biases in polygynous species. Evolution 58 (11): 2398-2408.
Lewis, S.; S. Benvenuti; L. Dall-Antonia; R. Griffiths; L. Money; T.N. Sherratt; S. Wanless \& K.C. Hamer. 2002. Sex-specific foraging behaviour in a monomorphic seabird. Proceedings of the Royal Society of London Series B 269: 1687-1693.

LimA, S.L. \& BeDNEKoFf, P.A. 1999. Back to the basis of antipredator vigilance: can nonvigilant animals detect attack? Animal Behaviour 58: 537-543.

Lima, S.L. \& L.M. DiLl. 1990. Behavioral decisions made under the risk of predation: a review and prospectus. Canadian Journal of Zoology 68: 619-640.

MACEDO, R.H. 2002. The avifauna: ecology, biogeography, and behavior, p. 242-265. In: P.S. Oliveira \& R.J. Marquis (Eds). The Cerrados of Brazil: ecology and natural history of a neotropical savanna. New York, Columbia University Press, 398p.

Magnhagen, C. 1991. Predation risk as cost of reproduction. Trends in Ecology and Evolution 6: 183-185.

MaLY, E.J. 1970. The influence of predation on the adult sex ratios of two copepod species. Limnology and Oceanography 15 (4): 566-573.

Martin, T.E. \& A.V. Badyaev. 1996. Sexual dichromatism in birds: importance of nest predation and nest location for females versus males. Evolution 50: 2454-2460.

MarTinS, T.L.F. 2004. Sex-specific growth rates in zebra finch nestlings: a possible mechanism for sex ratio adjustment. Behavioral Ecology 15 (1): 174-180.

Maruyama, P.K.; A.F. Cunha; E. Tizo-Pedroso; K. Del-claro. 2010. Relation of group size and daily activity patterns to southern lapwing (Vanellus chilensis) behaviour. Journal of Ethology 28 (2): 339-344.

MaYr, E. 1939. The sex ratio in wild birds. The American Naturalist 73 (745): 156-179.

McKellar, A.E.; M.M. Turcotte \& A.P. Hendry. 2009. Environmental factors influencing adult sex ratio in Trinidadian guppies. Oecologia 159: 735-745.

Michl, G.; J. Török; L.Z. Garamszegi \& L. Tóth. 2000. Sexdependent risk taking in the collared flycatcher, Ficedula albicollis, when exposed to a predator at the nestling stage. Animal Behaviour 59: 623-628.

Monaghan, P. \& R.G. Nager. 1997. Why don't birds lay more eggs? Trends in Ecology and Evolution 12: 270-274.

Montgomerie, R.; B. Lyon \& K. Holder. 2001. Dirty ptarmigan: behavioral modification of conspicuous male plumage. Behavioral Ecology 12: 429-438.

Myers, J. H. 1978. Sex ratio adjustment under food stress: maximization of quality or numbers of offspring? The American Naturalist 122 (984): 381-388.

Nur, N.; G.R. Geupel \& B. Grant. 2004. Estimates of adult survival, capture probability, and recapture probability: evaluating and validating constant-effort mist netting. Studies in Avian Biology 29: 63-70.

Oberweger, K. \& F. Goller. 2001. The metabolic cost of birdsong production. The Journal of Experimental Biology 204: 
3379-3388.

O'Donnell, C.F.J. 1996. Predators and the decline of New Zealand forest birds: an introduction to the hole-nesting bird and predator programme. New Zealand Journal of Zoology 23: 213-219.

Owens, I.P.F \& I.R. Hartley. 1998. Sexual dimorphism in birds: why are there so many different forms of dimorphism? Proceedings of the Royal Society of London Series B 265: 397-407.

PERRINS, C.M. 1996. Eggs, egg formation and timing of breeding. Ibis 138: 2-15.

Perry, E.F. \& D.E. Andersen. 2003. Advantages of clustered nesting for Least Flycatchers in North-Central Minnesota. The Condor 105 (4): 756-770.

Peters, W.D.; \& T.C. Grubb. 1983. An experimental analysis of sex-specific foraging in the Downy woodpecker, Picoides pubescens. Ecology 64 (6): 1437-1443.

Phillips, R.A.; J.R.D. Silk; B. Phalan; P. Catry \& J.P. Croxall. 2004. Seasonal sexual segregation in two Thalassarche albatross species: competitive exclusion, reproductive role specialization or foraging niche divergence? Proceedings of the Royal Society of London Series B 271: 1283-1291.

Pocklington, R. \& L.M. Dill. 1995. Predation on females or males: who pays for bright male traits? Animal Behaviour 49: 1122-1124.

Post, P. \& F. Gotmark. 2006a. Foraging behavior and predation risk in male and female Eurasian Blackbirds (Turdus merula) during the breeding season. The Auk 123 (1): 162-170.

Post, P. \& F. Gotmark. 2006b. Predation by sparrowhawks Accipiter nisus on male and female pied flycatchers Ficedula hypoleuca in relation to their breeding behaviour and foraging. Journal of Avian Biology 37: 158-168.

PröHL, H. 2002. Population differences in female resource abundance, adult sex ratio, and male mating success in Dendrobates pumilio. Behavioral Ecology 13 (2): 175-181.

Ralph, C. J.; E. H. Dunn. 2004. Monitoring bird populations using mist nets. Lawrence, Allen Press, Studies in Avian Biology 29, 211p.

Romey, W.L. \& A.C. Wallace. 2007. Sex and the selfish herd: sexual segregation within nonmating whirligig groups. Behavioral Ecology 18 (5): 910-915.

Rubolini, D.; F. Spina \& N. SaIno. 2004. Protandry and sexual dimorphism in trans-Saharan migratory birds. Behavioral Ecology 15 (4): 592-601.

Salamolard, M. \& H. Weimerskirch. 1993. Relationship between foraging effort and energy requirement throughout the breeding season in the wandering albatross. Ecology 7 (6): 643-652.

SANDERCock, B.K.; S.R. Beissinger; S.H. Stoleson; R.R. Melland \& C.R. HugHes. 2000. Survival rates of a neotropical parrot: implications for latitudinal comparisons of avian demography. Ecology 81 (5): 1351-1370.

SAnderCock, B.K.; T. SzéKely \& A. KosZTolányi. 2005. The effects of age and sex on the apparent survival of Kentish Plovers breeding in Southern Turkey. The Condor 107 (3): 583-596.

SARgEANT, A.B. 1972. Red Fox spatial characteristics in relation to Waterfowl predation. The Journal of Wildlife Management 36 (2): 225-236.

SARgEANT, A.B. \& L.E. Eberhardt. 1975. Death feigning by ducks in response to predation by Red Foxes (Vulpes fulva). The Journal of Wildlife Management 94 (1): 108-119.

Sargeant, A.B.; S.H. Allen \& R.T. Eberhardt. 1984. Red fox predation on breeding ducks in mid-continent North America. Wildlife Monographs 89: 1-41.

SELAS, V. 1993. Selection of avian prey by breeding sparrowhawks Accipiter nisus in southern Norway: the importance of size and foraging behavior of prey. Ornis Fennica 70: 144-154.

Shreeve, D.F. 1980. Differential mortality in the sexes of the Aleutian Gray-crowned Rosy Finch. American Midland Naturalist 104 (1): 193-197.

SICK, H. 1997. Ornitologia Brasileira: uma introdução. Rio de Janeiro, Nova Fronteira, $2^{\text {nd }}$ ed., 912p.

Sillett, T.S. \& R.T. Holmes. 2002. Variation in survivorship of a migratory songbirds throughout its annual cycle. Journal of Animal Ecology 71 (2): 296-308.

Silva, F.A.; E.D. Assad \& B.A. Evangelista. 2008. Caracterização climática do bioma Cerrado, p. 71-88. In: S.M. SANO; S.P. Almeida \& J.F. Ribeiro (Eds). Cerrado: ecologia e flora. Brasília, Embrapa Cerrado, 1279p.

Slagsvold, T.; S. Dale \& A. Kruszewicz. 1995. Predation favours cryptic coloration in breeding male pied flycatchers. Animal Behaviour 50: 1109-1121.

Sogge, M.K.; J.C. Owen; E.H. Paxton; S.M. Langridge \& T.J. Koronkiewicz. 2001. A targeted mist net capture technique for the Willow Flycatcher. Western Birds 32: 167-172.

South, J.M. \& T.F. Wright. 2002. Nestling sex ratios in the YellowNaped Amazon: no evidence for adaptive modification. The Condor 104 (2): 437-440.

Stevens, L.E.; B.T. Brown \& K. Rowell. 2009. Foraging ecology of Peregrine falcons (Falco peregrines) along the Colorado River Grand Canyon, Arizona. The Southwestern Naturalist 54 (3): 284-299.

Stiver, K.A.; J.K. Desjardins; J.L. Fitzpatrick; B. NefF; J.S. Quinn \& S. BALShine. 2007. Evidence for size and sex-specific dispersal in a cooperatively breeding cichlid fish. Molecular Ecology 16: $2974-2984$.

Stoleson, S.H. \& S.R. Beissinger. 2001. Does risk of nest failure or adult predation influence hatching patterns of Greenrumped Parrotlet? The Condor 103 (1): 85-97.

Sun, Y.; J.E. Swenson; Y. Fang; S. Klaus \& W. Scherzinger. 2003. Population ecology of the Chinese grouse, Bonasa sewerzowi, in a fragmented landscape. Biological Conservation 110: 54-61.

Svensson, J. 1997. Sex differences in habitat distribution of a planktonic copepod, Eudiaptomus gracilis. Ecography 20 (4): 407-416. 
Swennen, C.; P. Duiven \& L.A. Reyrink. 1979. Notes on the sex ratio in the Common Eider Somateria mollissima (L.). Ardea 67: 54-61.

Taylor, T. \& D. Parkin. 2008. Sex ratios observed in 80 species of parrots. Journal of Zoology 276 (1): 89-94.

Tinbergen, J.M. \& M.W. Dietz. 1994. Parental energy expenditure during brood rearing in the great tit (Parus major) in relation to body mass, temperature, food availability and clutch size. Functional Ecology 8: 563-572.

TRAIL, P. 1987. Predation and antipredator behavior at Guianan cock-of-the-rock leks. The Auk 104: 496-507.

VAN Der VeEn, I.T. 1999. Effects of predation risk on diurnal mass dynamics and foraging routines of yellowhammers (Emberiza citrinella). Behavioral Ecology 10: 545-551.

Veasey, J.S.; D.C. Houston \& N.B. Metcalfe. 2000. Flight muscle atrophy and predation risk in breeding birds. Functional Ecology 14: 115-121.

WARD, S. 1996. Energy expenditure of female barn swallows,
Hirundo rustica during egg formation. Physiological Zoology 68: 930-951.

Wheelwright, N.T.; G. Trussell; J.P. Devine \& R. Anderson. 1994. Sexual dimorphism and population sex ratios in juvenile Savannah Sparrows. Journal of Field Ornithology 65 (4): 520-529.

Williams, D.A. \& K. Rabenold. 2005. Male-biased dispersal, female philopatry, and routes to fitness in a social corvid. Journal of Animal Ecology 74 (1): 150-159.

WiLLIS, E.O. 1961. A study of nesting ant-tanagers in British Honduras. The Condor 63: 479-503.

WILSON, K. \& I.C.W. HARDY. 2002. Statistical analysis of sex ratios: an introduction, p. 48-92. In: I.C.W. Hardy (Ed.). Sex Ratios: Concepts and Research Methods. Cambridge, Cambridge University Press, 438p.

ZuK, M. \& G.R. KolLuRu. 1998. Exploitation of sexual signals by predator and parasitoids. The Quarterly Review of Biology 73 (4): 415-438.

Submitted: 24.III.2010; Accepted: 29.XI.2010.

Editorial responsibility: Kleber del Claro 